\title{
Study of Sylvilagus rabbit TRIM5 $\alpha$ species-specific domain: how ancient endoviruses could have shaped the antiviral repertoire in Lagomorpha
}

\author{
Ana Lemos de Matos ${ }^{1,2,3}$, Wessel van der Loo ${ }^{1}$, Helena Areal ${ }^{1,2}$, Dennis K Lanning ${ }^{3}$ and Pedro J Esteves ${ }^{1,4^{*}}$
}

\begin{abstract}
Background: Since the first report of the antiretroviral restriction factor TRIM5 $\alpha$ in primates, several orthologs in other mammals have been described. Recent studies suggest that leporid retroviruses like RELIK, the first reported endogenous lentivirus ever, may have imposed positive selection in TRIM5 $\alpha$ orthologs of the European rabbit and European brown hare. Considering that RELIK must already have been present in a common ancestor of the leporid genera Lepus, Sylvilagus and Oryctolagus, we extended the study of evolutionary patterns of TRIM5 $\alpha$ to other members of the Leporidae family, particularly to the genus Sylvilagus. Therefore, we obtained the TRIM5 $\alpha$ nucleotide sequences of additional subspecies and species of the three leporid genera. We also compared lagomorph TRIM5 $\alpha$ deduced protein sequences and established TRIM5 $\alpha$ gene and TRIM5 $\alpha$ protein phylogenies.

Results: The deduced protein sequence of Iberian hare TRIM5 $\alpha$ was $89 \%$ identical to European rabbit TRIM5 $\alpha$, although high divergence was observed at the PRYSPRY $v 1$ region between rabbit and the identified alleles from this hare species (allele 1: 50\% divergence; allele 2: 53\% divergence). A high identity was expected between the Sylvilagus and Oryctolagus TRIM5 $\alpha$ proteins and, in fact, the Sylvilagus TRIM5 $\alpha$ was $91 \%$ identical to the Oryctolagus protein. Nevertheless, the PRYSPRY v1 region was only 50\% similar between these genera. Selection analysis of Lagomorpha TRIM5 $\alpha$ proteins identified 25 positively-selected codons, 11 of which are located in the PRYSPRY v1 region, responsible for species specific differences in viral capsid recognition.

Conclusions: By extending Lagomorpha TRIM5 $\alpha$ studies to an additional genus known to bear RELIK, we verified that the divergent species-specific pattern observed between the Oryctolagus and Lepus PRYSPRY-domains is also present in Sylvilagus TRIM5 $\alpha$. This work is one of the first known studies that compare the evolution of the antiretroviral restriction factor TRIM5 $\alpha$ in different mammalian groups, Lagomorpha and Primates.
\end{abstract}

\section{Background}

Retroviruses are RNA viruses that, when infecting a host cell, produce a viral reverse transcriptase and a viral integrase that make a DNA copy of the viral genome and integrate it into the host genome, respectively [1]. The family Retroviridae comprises a diverse range of animal viruses, including the viral genus Lentivirus. Lentiviruses have been isolated from primates, domestic and wild felids, and a variety of domestic ungulates (goat, sheep, cattle and horse) [2]. Until recently, all known lentiviruses were classified as exogenous (transmitted

\footnotetext{
* Correspondence: pjesteves@mail.icav.up.pt

'Centro de Investigação em Biodiversidade e Recursos Genéticos, Campus

Agrário de Vairão, 4485-661 Vairão, Portugal

Full list of author information is available at the end of the article
}

horizontally from host to host) [3]. However, in 2007, Katzourakis and colleagues [4] reported the first endogenous lentivirus identified in any species, the rabbit endogenous lentivirus type K (RELIK), present in the genome of the European rabbit (Oryctolagus cuniculus). RELIK has subsequently been reported in other leporid genera (Lepus, Sylvilagus and Bunolagus), establishing it as at least 12 million years (My) old [5,6]. These striking observations demonstrate that lentiviruses are more widespread than previously thought, extending the host range to a different mammalian order, and demonstrate that lentiviruses can be endogenized [4-6].

The intense study of lentiviruses in the past 30 years, especially of human immunodeficiency viruses (HIV-1 and HIV-2), has been more recently accompanied by
C Biomed Central

() 2011 de Matos et al; licensee BioMed Central Ltd. This is an Open Access article distributed under the terms of the Creative Commons Attribution License (http://creativecommons.org/licenses/by/2.0), which permits unrestricted use, distribution, and reproduction in any medium, provided the original work is properly cited. 
the study of antiretroviral restriction factors, like the TRIM5 $\alpha$ protein, one of the members of TRIM family [7-11]. TRIM proteins contain three domains, which together constitute the canonical TRIpartite Motif, including an N-terminal RING domain, one or two BBox domains and a long Coiled-Coil (CC) domain [9-11]. TRIM5, like most TRIM proteins, also contains a C-terminal PRYSPRY domain, composed of four "variable loops" [9-11]. TRIM5 $\alpha$ is the largest isoform encoded by the TRIM5 gene and restricts infection by HIV-1 and other retroviruses, dependent on a speciesspecific sequence variation in the PRYSPRY domain, upon entry into the host cell cytoplasm and prior to reverse transcription $[7,8]$. Each TRIM5 $\alpha$ domain plays distinct roles in its antiviral restriction activity. The RING domain has been shown to confer E3 ubiquitin ligase activity crucial for anti-HIV restriction [12,13]. The B-box 2 domain influences recognition of the viral capsid by the C-terminal PRYSPRY domain [13-15]. The $\mathrm{CC}$ domain plays an important role in the restriction of viral infectivity and it is required for trimerization $[11,16]$. Particularly for HIV-1 and N-tropic murine leukemia virus (N-MLV) retroviruses, restriction specificity has been mapped to the PRYSPRY domain for HIV-1 and N-MLV restriction specificity is determined by both the CC and PRYSPRY domains $[9,17,18]$. Human TRIM5 $\alpha$ is not effective against HIV-1 but does inhibit $\mathrm{N}-\mathrm{MLV}$, while rhesus monkey TRIM5 $\alpha$ restricts both [19-22]. However, a single amino acid change (R332P) in the human TRIM5 $\alpha$ PRYSPRY domain causes it to behave like rhesus TRIM5 $\alpha$ with regard to HIV-1 restriction $[17,23]$. The PRYSPRY domain binds to the viral capsid, and the domain sequence variation determines the restriction specificity $[17,18,24-26]$. Recently, evidence from several studies began elucidating the detailed mechanism of TRIM5 $\alpha$ activity. Also, additional activities linked to viral restriction have been described, including a role in signal transduction, the promotion of innate immune signaling and recognition of the retroviral capsid lattice $[27,28]$. It has been suggested that direct binding of TRIM $5 \alpha$ to the viral capsid leads to disruption of specific inter-hexamer interfaces, causing structural damage to the capsid. TRIM5 $\alpha$ spontaneously forms a hexagonal lattice complementary to the capsid lattice, a molecular signature of retroviruses, which greatly stimulates TRIM5 $\alpha$ lattice formation $[29,30]$.

Evolutionary studies of primate TRIM5 $\alpha$ revealed a high ratio of non-synonymous to synonymous changes in the PRYSPRY domain [25,31-33]. The distribution of positively selected residues is not random, but falls in a very tight cluster at the beginning of the domain in a 13 amino acid "patch", essential for retroviral restriction and responsible, in part, for the species-specific restriction activity [31]. The same domain has also undergone length variation and segmental duplications in different primate lineages [25]. However, polymorphisms found in the TRIM5 $\alpha$ coding sequence for multiple individuals from two divergent lineages of Old World monkeys (rhesus macaque and sooty mangabey), indicated that specificity varies not only between different species but also within species [34]. Despite the geographic separation and the divergence time ( $>8 \mathrm{My}$ ), both species presented a highly similar pattern of polymorphisms, which constitutes compelling evidence for long-term balancing selection at the TRIM5 locus [34]. Similar evidence of selection has been recently reported for the first intron of human TRIM5 gene, which may affect transcription factor-binding sites and TRIM5 transcriptional activity [35].

Although evolutionary and functional studies of TRIM5 $\alpha$ antiretroviral restriction activity have primarily focused on the primate lineage, TRIM5 orthologs have been reported in other mammalian genomes, e.g. mouse, rat, cow and European rabbit [36-39]. Active TRIM5 was identified in the European rabbit and the ability to restrict the replication of multiple unrelated retroviruses was also described [38]. Besides this leporid, Fletcher and co-workers [40] reported the restriction of divergent retroviruses by European brown hare (Lepus europaeus) TRIM5 $\alpha$ and also significant differences between both leporids' TRIM5 $\alpha$ PRYSPRY domains. These authors suggested that retroviruses like RELIK may have driven the speciation of the Old World rabbit and hare TRIM $5 \alpha$ orthologs. The order Lagomorpha is divided into two families, Ochotonidae and Leporidae, which diverged around $40 \mathrm{My}$ ago [41-43]. Ochotonidae contains only one extant genus, Ochotona, while the family Leporidae includes 11 genera where, Lepus, Sylvilagus and Oryctolagus, the most well-studied leporid genera, diverged around 12 My ago [41,42]. It has been suggested that the global development of temperate grasslands (7 to $5 \mathrm{My}$ ago) and the formation of the west Antarctic ice sheet (6.5 My ago) promoted the development of land bridges and consequent dispersal of the genus Lepus from North America through Asia and into Africa [41]. The New World Sylvilagus lineage initially remained in North America from which it more recently colonized South America [41]. The genus Oryctolagus is the only leporid genus native to Europe and consists of two subspecies, O. cuniculus cuniculus and O. cuniculus algirus, which diverged around 2 My ago. The subspecies $O$. c. algirus is restricted to the southwest region of the Iberian Peninsula and a few Atlantic islands, whereas O. c. cuniculus has essentially a manmade worldwide distribution and includes all domestic breeds [44].

As previously suggested, considering that RELIK must already have been present in a common ancestor of 
these leporid genera, the hypothesis that lentiviruses might have been the driving force of the leporid TRIM5 $\alpha$ conserved antiretroviral activity can be challenged by extending the study of evolutionary patterns of TRIM $5 \alpha$ to other members of the Leporidae family, particularly to the New World Sylvilagus lineage. Therefore, in this study we have examined the TRIM5 $\alpha$ gene of additional subspecies and species of the three leporid genera: European rabbit subspecies (Oryctolagus cuniculus algirus), the Old World Iberian hare (Lepus granatensis) and European brown hare, and the New World brush rabbit (Sylvilagus bachmani).

\section{Results and Discussion}

\section{TRIM5 $\alpha$ divergence and phylogeny in Lagomorpha}

In this study, all the deduced TRIM $5 \alpha$ protein sequences obtained from leporids were aligned and compared to that previously described for the European rabbit (subspecies O. cuniculus cuniculus) [38] (Figure 1 ). To more completely assess the TRIM $5 \alpha$ gene in the Lagomorpha order, we also included American pika (Ochotona princeps) TRIM5 $\alpha$ nucleotide sequence retrieved from the whole genome shotgun (WGS) project (contig132533, Locus AAYZ01132534). During this work, we were able to bridge the American pika protein sequence gaps previously reported [40] (Figure 1).

The 2 My divergence between European rabbit subspecies apparently allowed the accumulation of one private residue in the $O . c$. algirus PRYSPRY v1 region $(351 \mathrm{H})$, different from O. c. cuniculus (Figure 1 and 2). Amino acid position 327 was described as being polymorphic in O. c. cuniculus [40], but O. c. algirus clones presented the same residue (327Q). In addition, two other polymorphisms were observed in O. c. algirus clones, one in the BB2 domain $(98 \mathrm{R} / \mathrm{C})$ and the other in the CC domain (148 N/K) (GenBank accession numbers JN541226 and JN541227).

The sequencing of European brown hare TRIM $5 \alpha$ confirmed the previously reported findings [40]. However, our Lagomorpha TRIM5 $\alpha$ alignment was somewhat different from that of Fletcher and colleagues [40] due to the inclusion of new species and a more complete American pika protein sequence. Out of the 30 PRYSPRY v1 region residues, we identified 15 differing positions between the European brown hare and the European rabbit, resulting in 50\% identity among v1 regions (Figure 1 and 3). TRIM5 $\alpha$ from another species of hare, Iberian hare, was also sequenced in this study. With fourteen clones from two individuals, we identified two alleles differing at three positions, each of them located within the PRYSPRY variable region $(332 \mathrm{~F} / \mathrm{L}$, $391 \mathrm{I} / \mathrm{T}$ and $427 \mathrm{C} / \mathrm{S}$ ) (GenBank accession numbers JN541228 and JN541229) (Figure 1 and 2). As expected, the overall identity between the TRIM $5 \alpha$ protein sequence of European rabbit and the TRIM5 $\alpha$ deduced protein sequence of the Iberian hare $(89 \%)$ was the same as that previously reported for the European brown hare (89\%) [40] which contrasted with the high divergence at the PRYSPRY v1 region (allele 1: 50\% divergence; allele 2: 53\% divergence) (Figure 3). The six amino acid positions previously identified as being polymorphic residues in the European brown hare [40] apparently were not polymorphic in the Iberian hare TRIM $5 \alpha$ sequenced clones. In fact, all the Iberian hare clones presented the same residues as the European brown hare allele 2 in these six positions (146T, 152A, 158K, 230L, 335V and 403Q). However, four positions of all the Iberian hare TRIM $5 \alpha$ sequenced clones $(185 \mathrm{~K}$, 253D, 279I and 294R) differed from both European brown hare alleles (185E, 253Y, 279T and 294H). None of them occurred in the PRYSPRY v1 region, which was identical among Lepus species, except for two polymorphic positions, one in the European brown hare allele $1(335 \mathrm{~F})$ and one in the Iberian hare allele 2 (332F).

The proposed leporid phylogeny estimates that the Lepus lineage diverged 12.80 My ago from the Oryctolagus/Sylvilagus clade, and that the Sylvilagus and Oryctolagus genera diverged $10 \mathrm{My}$ ago $[41,42]$. To extend the study of leporid TRIM $5 \alpha$, we determined the TRIM $5 \alpha$ nucleotide sequence from brush rabbit (GenBank accession number JN541230). As the Sylvilagus and Oryctolagus genera are closely related, a higher identity between their TRIM5 $\alpha$ proteins was expected and, indeed, the brush rabbit TRIM5 $\alpha$ deduced protein sequence was 91\% identical to the European rabbit protein (Figure 1). However, such increase in similarity was not observed at the PRYSPRY v1 region ( $50 \%$ similar between these species; Figure 3). From the seven clones obtained for this species, no polymorphisms were observed.

The high divergence obtained in the PRYSPRY v1 region could be explained by gene conversion with adjacent genes. Gene conversion has been reported in other mammalian genes. For example, in leporids, a gene conversion event was observed between the two chromosomally adjacent genes CCR 2 and CCR 5 , where the sequence motif ${ }_{194} \mathrm{QTLKMT}_{199}$ of the CCR5 protein was replaced by the HTIMRN motif which is characteristic of CCR2 $[45,46]$. In the present study, none of the chromosomally adjacent genes showed clear evidence of gene conversion with TRIM5, making this explanation unlikely. Furthermore, no significant BLAST matches were obtained during searches of the mammalian NCBI database. No evidence of recombination between alleles was observed.

To obtain evidence of within-species variation, the number of individuals per species should be significant. In this study, the number of individuals was low, 

MASA ILANMKEEVTCPICLELLVEPLS I DCGHSFCQAC I TANYESMI AKEMESRCPVCRIGYQLENLRPNRHVAN MASA I LANMKEEVTCPICLELLVEPLS IDCGHSFCQACI TANYESMIAKEMESRCPVCRISYQLENLRPNRHVAN MASA I LANMKEEV TCPICLELLVEPLS IDCGHSFCQACITANYESMIAKEMESRCPVORISYQLENLRPNRHVAN MAAAVLANVKEEVICPICLELLVEPLS IDCGHSFCQACITANYESMIAKEMESRCPVORIGYQLENLRSNRHVAN MASAVLENMKEEVMCPICLELLVEPQSLDCGHSFCSACITGNYKSSEAKDVESRCPVCRVSYQLENLRPNRHVAN

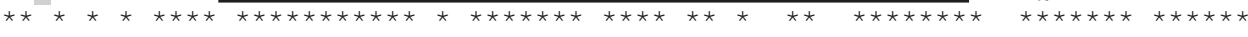
BB2 CC IVEKINEIKLSSEE GQKQEHCARHGEKLLLFCKEDGKVICWLCERSQEHRGHHTFLMEEVAQEYQEKLQSALNNL 150

\section{Leeu}

Legr

Syba

ocpr

IVEKINEIKLSSEE GQKQEHCARHGEKLLLFCKEDGKVICWLCERSQEHRGHHT FLMEEVAQEYQEKLQSALKNL IVEKMNEIKFCSEE GQKQEHCARHGEKLLLFCKEDGKVICWLCEHSQEHRGHHT FLIEEIAQEYQEKLQSALNNL IVEKMNE IKFCSEEGQKQEHCARHGEKLLLFCKEDGKVICWLCEHSQEHRGHHTFLIEEIAQEYQEKLQSTLNNL IVEKINEIKLSSEE GQKQEHCARHGEKLLLFCKEDGKVICWLCERSQEHRRHHT FLIEEIAQEYQEKLQSALHNL IIERIKELDLSSEEEQKVDLCAHHQEKLLLFCKEDGKLICWLCERSQKHRGHHTFLIEDVVQEYQEKLQEALKKL

Orcucu Orcual Leeu Legr Syba Ocpr

MTKQEEAEKLKAGIQQEITSWKNQLQKERQNIQAEFKHLKDILDSEEQDELQKLEEEKGHI LKSMEESKHELIQQ 225 MTKQEEAEKLKAGIQQEITSWKNQLQKERQNIQAEFKHLKDI LDSEEQDELQKLEEEKGH I LKSMEESKHELIQQ MTKQEEAEKLKAGIQQEITSWKNQLQKERQNIQAEFKHLKDI LDSGEQDELQKLEEEKGH I LKSMEESKNELIQQ MAKQEEAKKLKAGIQQEITSWKNQLQKERQNIQAKFKHLKDILDSGEQDELQKLEEEKGH I LKSMEESKNELIQQ MTKQEEAGKLKAGIQQEITSWKNQLQKERQNIRAEFKHLKDI LDSEEQDELQKLEEEEGHI LKSMEESKNELIQQ $\frac{\text { MKEQEESEKLKADVQEEITSWKDQIQGERLTIESEFQQLKDILDSMEQNELQKLKEEEDHILSSLAESKSQLTQQ }}{\star \star \star \star \star \star \star ~}$ PRYSPRY SQVIQNHISDLENCLQRPTIEMLQDVNDI IYRTETETLKKPKTFPEKERKSFQI HELKRTMQMFQDLRH SQVIQNHISDLENCLQRPT IEMLQDVNDI IYRTETFTLKKPKTFPEKERKSFQIHELKRTMQMFQDLRHAQRYWV SQVLRNH ISDLENRLQRPAVEMLQDVNYI INRTETFTLKKPKTFPEKKRKSFQTDELKRTLQVFQDLRHARRYWV SQVLQNHESDLENRLQRPAVEMLQDVNDI INRTETFTLKKPKTFPEKKRKSFQ I DELKRTLQVFQDLRRARRYWV SQVIQNHESDLENCLQRPAIEMLQDVNDILNRTETFTLKKPKTFPEKERKSFQ I HELKRTMQMFQDLRHARRYWV

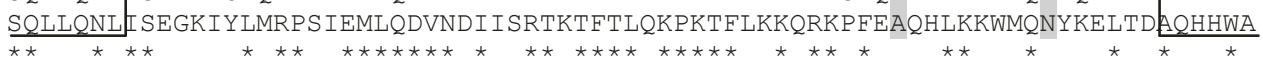
HVTLTPSNNQNIVVSENKRQVMYVHYHQRLNLFSLSDDHGFRY--GTRQNYFDGILGCPSITSGKHYWEVDVSGK 375 HVTLTPSNNQNIVVSENKRQVMYVHYQQRLNLFSLSDDHGFRY--GTRQNHF DGI LGCPS ITSGKHYWEVDVSGK HVTLTPSNNQNIVVSENKRQVMYVHYQKHGSLFLFKDNYGCQY-EGIKQNYF DGI LGCPS ITSGKHYWEVDVSGK HVTLTPSNNQNIVVSENKRQVMYVHYQKHGSLFLVKDNYGCQY-EGIKQNYFDGI LGCPS ITSGKHYWEVDVSGK DLTLTPSNNQNI IVSENKRQVMYVHYKQQPSFFPFNDNYVRQY--ETGQNYF DGI LGCPS ITSGKHYWEVDVSGK NVTLTPSNNPNIVISENKREVKYTEFFHGNVSFGEKSTYNLTGI PVLTRPYSEGILGHPAFT SGKNYWEVDVSEK

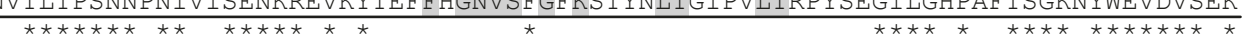

\section{V1}

Orcucu

Orcual

Leeu

Legr

Syba

Ocpr

Orcucu

Orcual

Leeu

Legr

Syba

Ocpr
SAWILGVYGPPLLQTTTSFAYEQVSKYRPINGYWVIGLQIQYIS-FEENAISLTPIVPPSRIGVFIDYEAGIVSF 450 SAWILGVYGPPLLQTTTSFAYEQVSKYRPINGYWVIGLQIQYIS-FEENAISLTPIVPPSRIGVFI DYEAGIVSF SAWILGVYGPPSLQTIKSFAYGQF SKYRPINGYWVIGWQNQY IS-YEENS ICLTPIVPPSCIGVFIDYEAGIVSF SAWILGVYGPPSLQTIKSFAYGQFSKYQP INGYWVIGWQNQY IS-YEENS ICLTPIVPPSCIGVFIDYEAGIVSF SAWILGVRGLPLLQTTTS FAFGQASKYRP INGYWVIGLQNKY IS-FEENA ISLTPIVPLSRIGVFI DYEAS IVSF

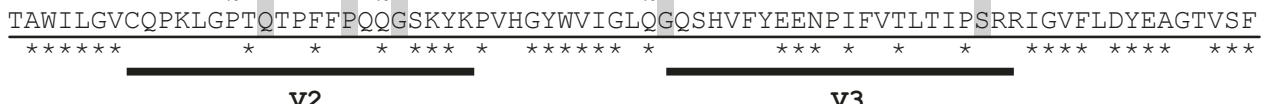

\section{V2}

FSVTQHKFLIYKFSACSFSKEVFPYFNPMHCPKPMTICELSC 492

FSVTQHKFLIYKFSACSFSKEVFPYFNPMHCPKPMTICELSC FSVTQHTFLIYKFSACSFAEEVFPYFNPMQCPKPMTICQMSC FSVTQHTFLIYKFSACSFAEEVFPYFNPMQCPKPMTICQMSC FSVTQHKFLIYKFAACSFSKEVFPYFNPMQCPKPMTICQLSC $\frac{\text { FSVTHSVYLMYKFSGCSFSNEVFPYFNPMTCPRPMTLC }----}{\star \star \star \star \star * ~}$

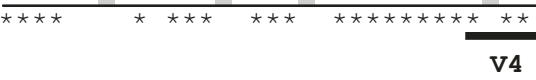

Figure 1 Lagomorpha TRIM5 $\alpha$ deduced protein sequences. Alignment of TRIM5 $\alpha$ deduced protein sequences from European rabbit, Oryctolagus cuniculus cuniculus (Orcucu) and Oryctolagus cuniculus algirus (Orcual) subspecies, European brown hare (Leeu - allele 1), Iberian hare (Legr - allele 1), brush rabbit (Syba) and American pika (Ocpr). Only allele 1 for Iberian hare is represented, as all the differences between both alleles are reported in the main text. European brown hare sequenced alleles were similar to those previously reported (Genbank accession numbers HM768824, HM768825) [40]. RING domain, B-box type 2 (BB2) domain, Coiled Coil (CC) domain and PRYSPRY domain, with its variable regions ( $\mathrm{v} 1, \mathrm{~V} 2, \mathrm{v} 3$ and $\mathrm{v} 4)$, are indicated. Positively-selected codon positions are shaded; asterisk $(*)$, identical residue between all species. 


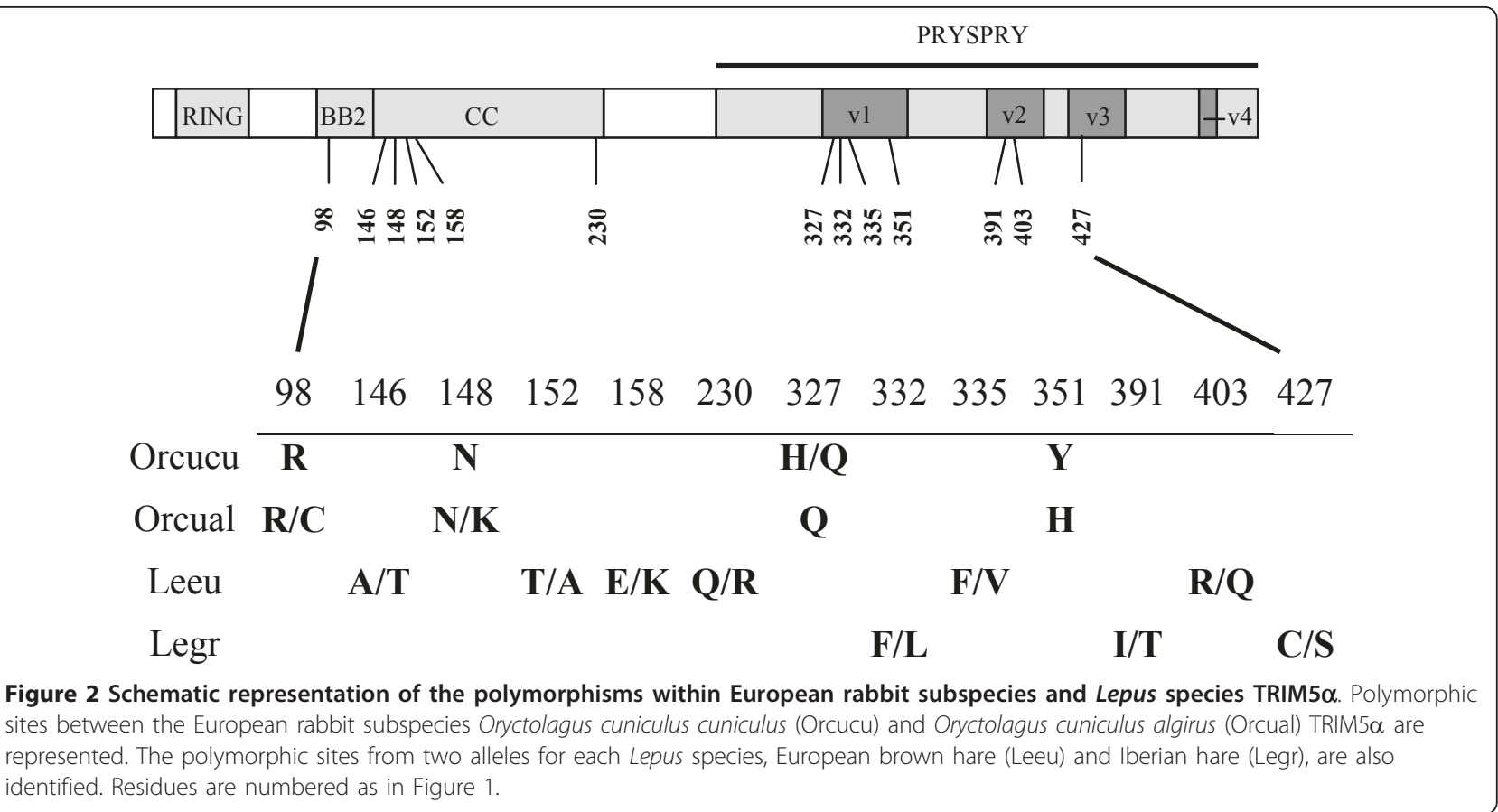

limiting the accuracy of the observed polymorphisms. However, it cannot be ruled out that some of the sites that appeared to be variable between species are polymorphisms present within species, especially when considering the two closely related Lepus species. A case of trans-species polymorphism was reported in a study of the evolution of the immunoglobulin heavy chain variable region in Oryctolagus and Lepus [47]. In light of the previously described long-term balancing selection on primate TRIM5 $\alpha[34,35]$, this scenario cannot be excluded in leporids.

Lagomorpha TRIM $5 \alpha$ phylogenetic trees, based on nucleotide, including all described alleles, and amino acid deduced sequences, were obtained with the Maximum Likelihood method (Figure 4). TRIM5 $\alpha$ nucleotide and amino acid sequences of three primates (human (Homo sapiens), chimpanzee (Pan troglodytes) and rhesus monkey (Macaca mulatta)), and TRIM6 nucleotide and amino acid sequences of European rabbit and human were also included. The trees typology was coincident with the known species tree $[41,42,48,49]$, where TRIM6 sequences represented an outgroup, and primate and lagomorph TRIM $5 \alpha$ formed two orthologs groups. Due to the identical typology between the two sets of data, only the tree based on nucleotide sequences is represented in Figure 4.

\section{Inference of positive selection in Lagomorpha TRIM5 $\alpha$ protein}

To identify a specific pattern of nucleotide substitution in the leporid TRIM5 $\alpha$ protein, synonymous and nonsynonymous substitution rates were estimated using the Nei-Gojobori method [50] and a non-synonymous to synonymous substitution ratio $\left(\mathrm{d}_{\mathrm{N}} / \mathrm{d}_{\mathrm{S}}\right)$ was calculated (Table 1). Under neutrality, coding sequences are expected to present a ratio of non-synonymous substitutions $\left(\mathrm{d}_{\mathrm{N}}\right)$ over synonymous substitutions $\left(\mathrm{d}_{\mathrm{S}}\right)$ that does not significantly deviate from $1\left(\omega=\mathrm{d}_{\mathrm{N}} / \mathrm{d}_{\mathrm{S}}=1\right)$, while significant deviations may be interpreted as either the

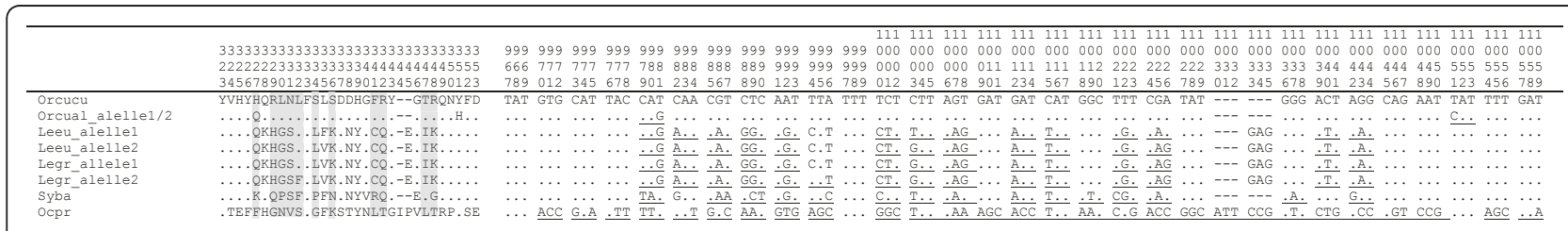

Figure 3 Amino acid and nucleotide sequences of Lagomorpha PRYSPRY v1 region. Amino acid and nucleotide sequences of PRYSPRY v1 region are represented for European rabbit subspecies Oryctolagus cuniculus cuniculus (Orcucu) and Oryctolagus cuniculus algirus (Orcual), European brown hare (Leeu - allele 1 and 2), Iberian hare (Legr - allele 1 and 2), brush rabbit (Syba) and American pika (Ocpr). The shadowed region on the amino acid representation corresponds to positively-selected sites obtained by REL analysis. Non-synonymous substitutions are underlined on the nucleotide sequences of Lagomorpha PRYSPRY v1 region. Residues are numbered as in Figure 1. 


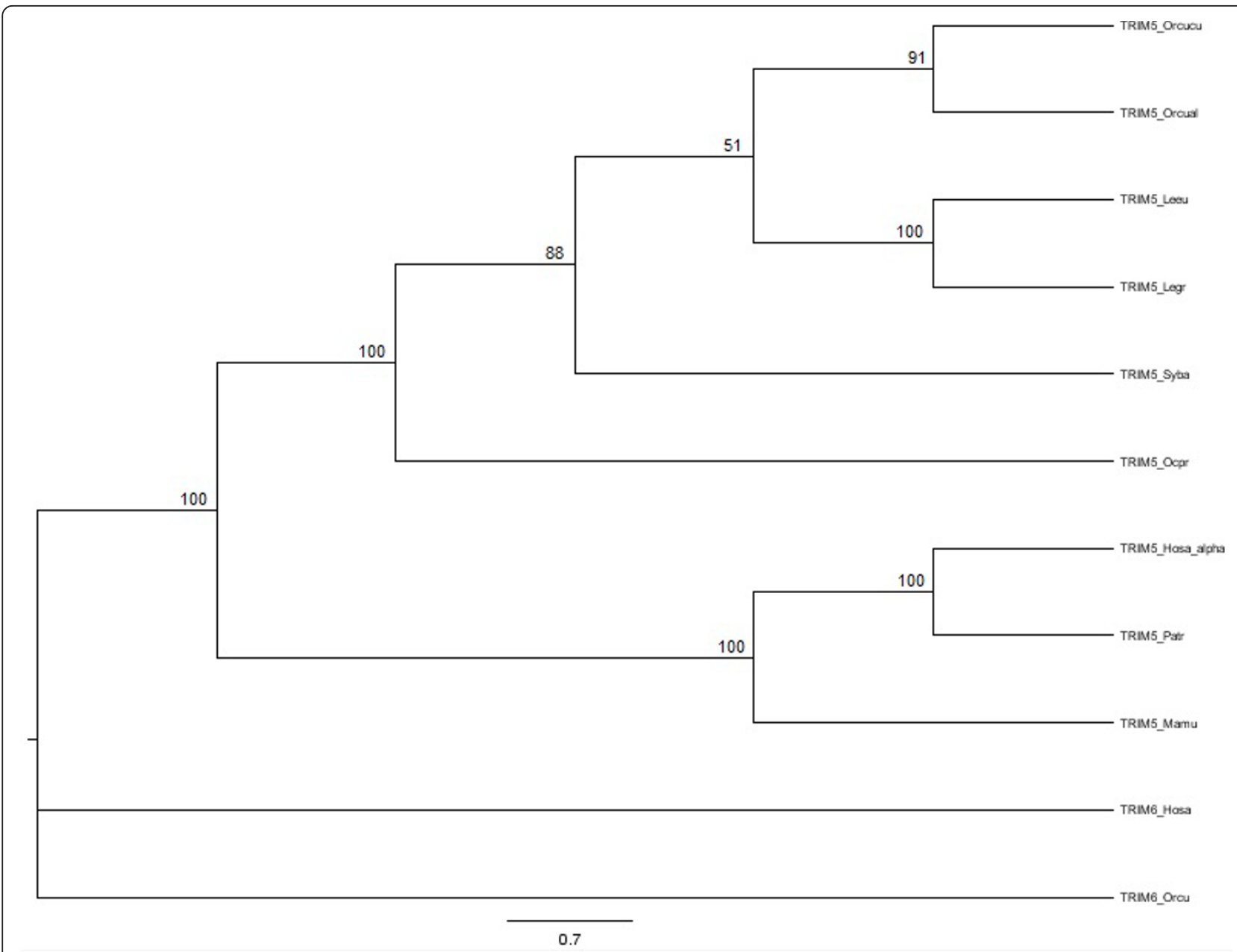

Figure 4 Maximum Likelihood phylogenetic trees of lagomorph and primate TRIM5 $\alpha$ and TRIM6 nucleotide sequences. TRIM5 $\alpha$ nucleotide sequences from Lagomorpha and three primates (human (Hosa), chimpanzee (Patr) and rhesus monkey (Mamu)), and TRIM6 nucleotide sequences from European rabbit and human were used to construct a Maximum Likelihood phylogenetic tree. The analyses were performed with 1,000,000 generations and 1,000 bootstrap searches. The bootstrap values are indicated on the branches.

result of positive selection $(\omega>>1)$ or of negative selection $(\omega<<1)$. This simple analysis showed that the ratios obtained between genera ranged from 2.8 to 4.3 , clearly higher than 1 , suggesting that TRIM5 $\alpha$ is under strong positive selection.
The high variability of the PRYSPRY domain and the positive selection of TRIM $5 \alpha$ described in primates [18,25,31-33] prompted Fletcher and colleagues (2010) [40] to perform a codon-based selection analysis using the random effect likelihood (REL) model. With this

Table 1 Leporid TRIM5 $\alpha$ estimation of non-synonymous to synonymous substitution ratio $\left(d_{N} / d_{S}\right)$

\begin{tabular}{|c|c|c|c|c|c|c|c|}
\hline & Orcucu & $\begin{array}{l}\text { Orcual } \\
\text { allele1 }\end{array}$ & $\begin{array}{l}\text { Orcual } \\
\text { allele2 }\end{array}$ & $\begin{array}{c}\text { Leeu } \\
\text { allele1 }\end{array}$ & $\begin{array}{c}\text { Leeu } \\
\text { allele2 }\end{array}$ & $\begin{array}{c}\text { Legr } \\
\text { allele1 }\end{array}$ & $\begin{array}{c}\text { Legr } \\
\text { allele2 }\end{array}$ \\
\hline \multicolumn{8}{|l|}{ Orcucu } \\
\hline Orcual_allele1 & 1.5 & & & & & & \\
\hline Orcual_allele2 & 1.5 & 1.0 & & & & & \\
\hline Leeu_allele1 & 3.0 & 3.1 & 3.4 & & & & \\
\hline Leeu_allele2 & 2.9 & 2.9 & 3.2 & 3.0 & & & \\
\hline Legr_allele1 & 3.2 & 3.2 & 3.2 & 2.5 & 2.0 & & \\
\hline Legr_allele2 & 3.2 & 3.2 & 3.2 & 3.0 & 3.0 & n. a. & \\
\hline Syba & 2.8 & 2.9 & 2.9 & 4.1 & 3.8 & 4.3 & 4.1 \\
\hline
\end{tabular}

Oryctolagus cuniculus cuniculus (Orcucu), Oryctolagus cuniculus algirus (Orcual), European brown hare (Leeu), Iberian hare (Legr) and brush rabbit (Syba). n.a.- not applicable (no non-synonymous substitutions were observed). 
analysis, the authors identified 11 positively-selected codons, 4 of which were located in the PRYSPRY v1 region [40]. Using the same methodology and parameters, we identified 25 positively-selected codons, 20 of which are located in the PRYSPRY domain and, more specifically, 11 in the v1 region (Table 2). In Figure 3 the amino acid and nucleotide sequences of Lagomorpha PRYSPRY v1 region are represented and the non-synonymous substitutions are marked. It should be pointed out that the PRYSPRY domain was the site of the most intense positive selection in primates [31-33]; its v1 region was identified as the major determinant of anti-HIV-1 potency distinguishing the human and rhesus monkey TRIM5 $\alpha$ proteins [16-18,23-25,32]. The proposed evolutionary model for primate TRIM5 $\alpha$ in which a history of virus-host interactions led to species-specific adaptations [31] can be considered also for leporids. But again, the trans-species scenario between leporid species cannot be ruled out to explain the species-specific variations.
Our striking observation was visually reinforced by sliding-window analysis of TRIM $5 \alpha$ nucleotide divergence between species (Figure 5). Comparing Oryctolagus with other leporid genera that diverged about $12 \mathrm{My}$ ago, the nucleotide differences throughout the gene occurred primarily around 0.00-0.10 and 0.00-0.05 nucleotide replacements per site for Lepus and Sylvilagus species, respectively (Figure 5A, B and $5 \mathrm{C}$ ). Nevertheless, the nucleotide differences peak $(\sim 0.20)$ was observed around nucleotide position 1000, where the PRYSPRY v1 region is located (positions 967-1059). The 40 My separation between Ochotona and the leporids is apparent in the 0.30 to 0.60 nucleotide replacements per site when comparing American pika to European rabbit (Figure 5D). However, the peak in the v1 region is still clearly defined. These observations can be compared to the nucleotide differences among primates. The approximately 4.5-6 My of evolutionary divergence between human and chimpanzee $[48,49,51]$ resulted in a nucleotide difference of 0-0.03

Table 2 Positively-selected codon positions in the Lagomorpha TRIM5 $\alpha$ deduced protein sequences

\begin{tabular}{|c|c|c|c|c|c|c|c|c|c|}
\hline Codon $^{a}$ & Normalized E [dN-dS] & $\begin{array}{l}\text { Posterior } \\
\text { Probability }\end{array}$ & $\begin{array}{l}\text { Bayes } \\
\text { Factor }\end{array}$ & Region & Orcu $^{b}$ & Leeu & Legr & Syba & Ocpr \\
\hline 3 & 0.30 & 1.00 & 795 & - & $S^{0}$ & $\mathrm{~S}^{0}$ & $S^{0}$ & $\underline{A}^{0}$ & $\mathrm{~S}^{0}$ \\
\hline 148 & 0.29 & 0.99 & 224 & CC & $\mathrm{N}^{0} / \mathrm{K}^{+}$ & $\mathrm{N}^{0}$ & $\mathrm{~N}^{0}$ & $\overrightarrow{\mathrm{H}^{0 /+}}$ & $\mathrm{K}^{+}$ \\
\hline 196 & 0.29 & 0.99 & 179 & CC & $\mathrm{E}^{-}$ & $\underline{G}^{0}$ & $\underline{G}^{0}$ & $\mathrm{E}^{-}$ & $\underline{M}^{0}$ \\
\hline 279 & 0.30 & 1.00 & 1913 & - & $!^{0}$ & $\bar{T}^{0}$ & $!^{0}$ & $!^{0}$ & $\bar{A}^{0}$ \\
\hline 288 & 0.29 & 0.99 & 178 & - & $\underline{\mathrm{M}}^{0}$ & $\underline{\mathrm{V}}^{0}$ & $\underline{\mathrm{j}}^{0}$ & $\overline{\mathrm{M}}^{0}$ & $\overline{\mathrm{N}}^{0}$ \\
\hline 327 & 0.30 & 1.00 & 6611 & v1 & $H^{0 /+} / Q^{0}$ & $\mathrm{Q}^{0}$ & $\mathrm{Q}^{0}$ & $\overline{\mathrm{K}^{+}}$ & $\underline{F}^{0}$ \\
\hline 329 & 0.30 & 1.00 & 578 & $\mathrm{v} 1$ & $\mathrm{R}^{+}$ & $\mathrm{H}^{0 /+}$ & $\mathrm{H}^{0 /+}$ & $Q^{0}$ & $\overline{\mathrm{G}}^{0}$ \\
\hline 330 & 0.30 & 1.00 & 35572 & v1 & $\underline{L}^{0}$ & $\underline{G}^{0}$ & $\underline{\mathrm{G}}^{0}$ & $\underline{p}^{0}$ & $\overline{\mathrm{N}}^{0}$ \\
\hline 331 & 0.30 & 0.99 & 405 & $\mathrm{v} 1$ & $\bar{N}^{0}$ & $\bar{s}^{0}$ & $\overline{S^{0}}$ & $\bar{s}^{0}$ & $\underline{V}^{0}$ \\
\hline 332 & 0.30 & 1.00 & 33711 & $\mathrm{v} 1$ & $\underline{L}^{0}$ & $\underline{L}^{0}$ & $\underline{L}^{0}$ & $\underline{F}^{0}$ & $S^{0}$ \\
\hline 334 & 0.30 & 1.00 & 5055 & $\mathrm{v} 1$ & $S^{0}$ & $\underline{L}^{0}$ & $\underline{L}^{0}$ & $\underline{p}^{0}$ & $\underline{G}^{0}$ \\
\hline 336 & 0.30 & 0.99 & 294 & $\mathrm{v} 1$ & $\mathrm{~S}^{0}$ & $\overline{\mathrm{K}^{+}}$ & $\overline{\mathrm{K}}^{+}$ & $\overline{\mathrm{N}}^{0}$ & $\overline{\mathrm{K}^{+}}$ \\
\hline 341 & 0.30 & 1.00 & 483 & $\mathrm{v} 1$ & $\underline{F}^{0}$ & $\underline{C}^{0}$ & $\underline{C}^{0}$ & $\mathrm{R}^{+}$ & $\underline{L}^{0}$ \\
\hline 342 & 0.30 & 1.00 & 574 & $\mathrm{v} 1$ & $\mathrm{R}^{+}$ & $\overline{\mathrm{Q}}^{0}$ & $\overline{\mathrm{Q}}^{0}$ & $\mathrm{Q}^{0}$ & $\mathrm{~T}^{0}$ \\
\hline 347 & 0.30 & 0.99 & 320 & $\mathrm{v} 1$ & $T^{0}$ & $!^{0}$ & $!^{0}$ & $T^{0}$ & $\underline{L}^{0}$ \\
\hline 348 & 0.30 & 1.00 & 691 & $\mathrm{v} 1$ & $\mathrm{R}^{+}$ & $\overline{\mathrm{K}}^{+}$ & $\overline{\mathrm{K}}^{+}$ & $\mathrm{G}^{0}$ & $\bar{T}^{0}$ \\
\hline 391 & 0.30 & 1.00 & 3822 & v2 & $T^{0}$ & $!^{0}$ & $!^{0}$ & $\overline{\mathrm{T}^{0}}$ & $Q^{0}$ \\
\hline 396 & 0.30 & 0.99 & 438 & v2 & $Y^{0}$ & $Y^{0}$ & $Y^{0}$ & $\underline{F}^{0}$ & $\underline{p}^{0}$ \\
\hline 399 & 0.30 & 0.99 & 368 & v2 & $\underline{v}^{0}$ & $\underline{F}^{0}$ & $\mathrm{~F}^{0}$ & $\underline{A}^{0}$ & $\underline{G}^{0}$ \\
\hline 415 & 0.28 & 0.98 & 134 & v3 & $\overline{1}^{0}$ & $\overline{\mathrm{N}}^{0}$ & $\overline{\mathrm{N}}^{0}$ & $\overline{\mathrm{N}}^{0}$ & $\overline{\mathrm{G}}^{0}$ \\
\hline 434 & 0.30 & 0.99 & 432 & v3 & $\underline{p}^{0}$ & $\underline{p}^{0}$ & $\underline{P}^{0}$ & $\underline{L}^{0}$ & $S^{0}$ \\
\hline 457 & 0.29 & 0.99 & 217 & - & $\mathrm{K}^{+}$ & $\bar{T}^{0}$ & $\bar{T}^{0}$ & $\mathrm{~K}^{+}$ & $\underline{\mathrm{V}}^{0}$ \\
\hline 464 & 0.30 & 0.99 & 416 & - & $S^{0}$ & $S^{0}$ & $S^{0}$ & $A^{0}$ & $\bar{S}^{0}$ \\
\hline 469 & 0.30 & 0.99 & 418 & - & $S^{0}$ & $\underline{A}^{0}$ & $\underline{A}^{0}$ & $\bar{S}^{0}$ & $S^{0}$ \\
\hline 480 & 0.30 & 1.00 & 639 & - & $\mathrm{H}^{0 /+}$ & $\overline{\mathrm{Q}}^{0}$ & $\overline{\mathrm{Q}}^{0}$ & $\mathrm{Q}^{0}$ & $T^{0}$ \\
\hline
\end{tabular}

European rabbit (Orcu), European brown hare (Leeu), Iberian hare (Legr), brush rabbit (Syba) and American pika (Ocpr).

${ }^{\text {a }}$ Codon positions are numbered according to the alignment in Figure 1.

${ }^{\mathrm{b}}$ Single amino acid = same for both Orcu subspecies, Oryctolagus cuniculus cuniculus (Orcucu) and Oryctolagus cuniculus algirus (Orcual); Two amino acids divided by "l" = Orcucu amino acid/Orcual amino acid

Codon physical-chemical properties are also represented: Underlined codon $=$ non-polar amino acid; non-underlined codon $=$ polar amino acid; ${ }^{+}=$positive amino acid; ${ }^{-}=$negative amino acid ${ }^{0}=$ neutral amino-acid . 


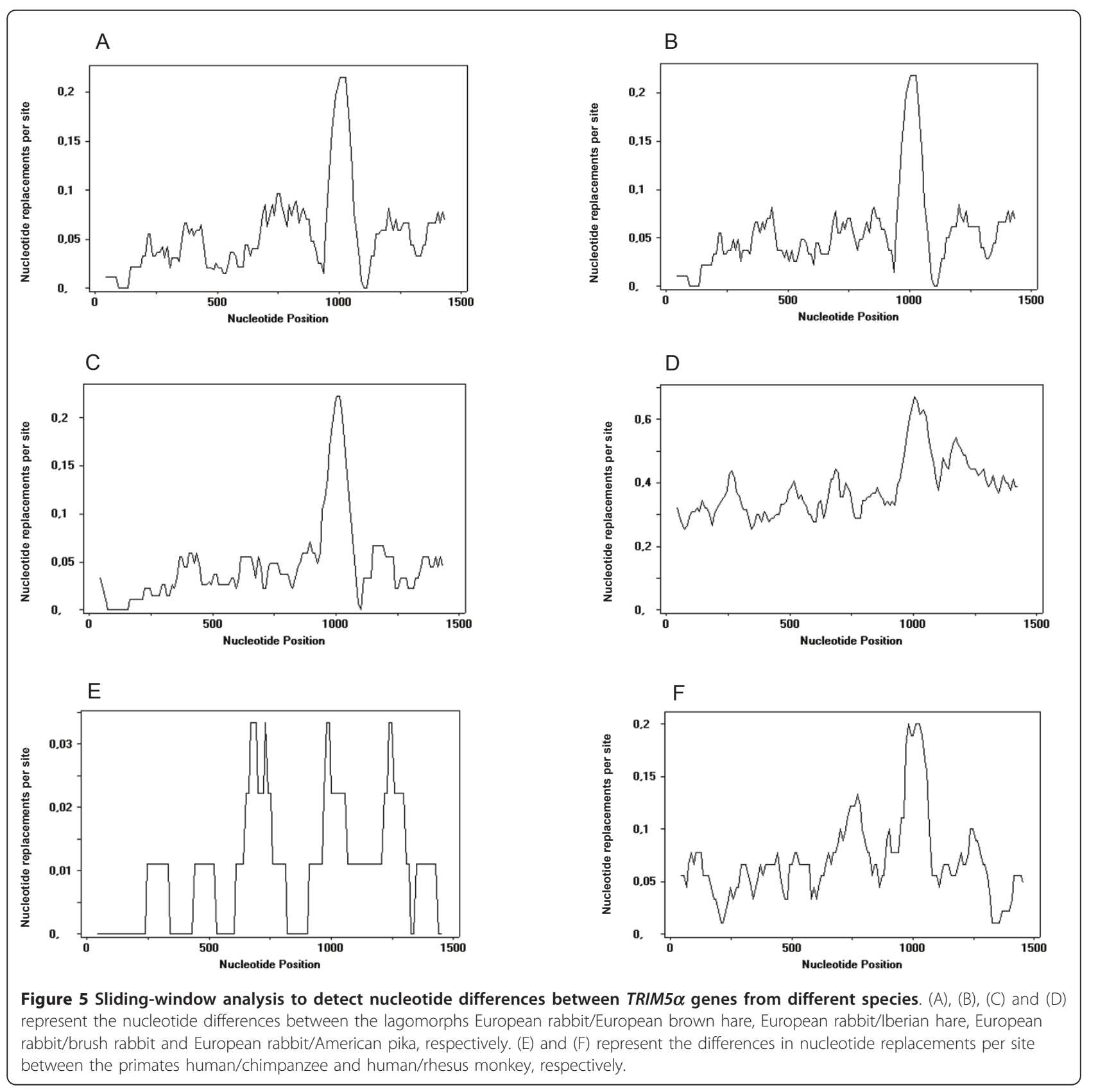

nucleotide replacements per site, although some peaks are still defined, including one around the nucleotide position 1000 (Figure 4E). Comparison of the human and rhesus monkey also revealed a peak in the PRYSPRY v1 region (Figure 5F), variance similar to that observed among leporid genera $(\sim 0.20)$, although the average nucleotide differences are higher than between leporids (0.00-0.15 nucleotide replacements per site), which is consistent with the $<31$ My divergence time between human and rhesus monkey [18,31].

The interest in studying ancient extinct viruses (paleoviruses) in primate genomes has increased in the past few years. However, using sequences of "modern" viruses to identify paleoviruses has been a problem and some new strategies began to be applied. The approach broadly used consists in looking for signatures of evolutionary adaptation in antiviral genes [52]. Several primate antiviral genes have already been studied and positive selection was inferred, including the focus of this paper, TRIM5 $\alpha$ [e.g. $[31,33,53,54]]$. The detection of extensive diversity in primate TRIM5 $\alpha$ led the scientific community to speculate that endogenous retroviruses and/or exogenous lentiviral pathogens may have exerted selective pressure on this host restriction factor and, in 
the specific case of human TRIM5 $\alpha$, that the acquisition of resistance to specific ancient endogenous retroviruses may be responsible for our susceptibility to HIV-1 in the present-day $[31,32,55]$.

Assuming that selective pressure acts on the TRIM5 $\alpha$ region that recognizes variation in the capsid of retroviruses, it was predicted that the PRYSPRY v1 region represents the interface with the capsid [18,25,31,32]. Recent studies showed that RELIK is highly similar structurally to modern-day exogenous lentiviruses and that the capacity of the capsid to form a protein-protein complex with CypA is maintained [56]. CypA is a host cell peptidyl proline isomerase that binds to the retroviral capsid $[57,58]$. With the absence of known exogenous lentiviruses affecting leporids, endogenous retroviruses such as RELIK were suggested to dominate leporid TRIM5 $\alpha$ evolution after host germline infection [40]. Our prediction was that the TRIM5 $\alpha$ protein from the third leporid genus known to harbor RELIK, the New World genus Sylvilagus, should also reflect selective pressure patterns in specific regions previously reported for the Old World Oryctolagus and Lepus genera. In fact, despite Sylvilagus being more closely related to Oryctolagus, the sequence divergence in TRIM $5 \alpha$ is comparable to that found between European brown hare, Iberian hare and the two O. cuniculus subspecies, particularly in the PRYSPRY v1 region where the majority of positively-selected codons is concentrated.

The current release of both European rabbit and American pika genomes has increased the opportunities to identify other Lagomorpha endogenous retroviruses, remnants of ancient extinct viruses. At the same time, while comparing sequence data from several orthologs of lagomorph antiviral genes, signatures of evolutionary change in these antiviral genes could date when different ancient viral pathogens acted. Of course, it is not correct to fully assume that only one ancient retrovirus was responsible for selectively pressuring a specific antiviral gene and vice versa, or that an exogenous lentiviruses did not play a preponderant role in TRIM5 $\alpha$ Lagomorpha evolution. However, until other endogenous retroviruses are identified in leporid or even lagomorph genomes and due to the absence of known exogenous lentiviruses infecting leporids, we speculate that endogenous retroviruses like RELIK could have acted as evolutionary forces on leporid TRIM $5 \alpha$.

\section{Conclusions}

This evolutionary study on Lagomorpha TRIM5 $\alpha$ gene shows a remarkable differentiation in the PRYSPRY v1 region suggesting that this gene has evolved under a high selective pressure within the Lagomorpha order. With the exception of studies on the primate lineage, this is one of the first comprehensive and detailed evolutionary studies of the antiretroviral restriction factor TRIM5 $\alpha$. Furthermore, the similarities observed in the species split within primates and lagomorphs allow the establishment of comparisons of the evolutionary patterns observed in TRIM $5 \alpha$ gene.

\section{Methods}

\section{Samples, RNA extraction and cDNA synthesis}

Liver samples from one European rabbit (subspecies Oryctolagus cuniculus algirus; Orcual), two European brown hares (Lepus europaeus; Leeu) and two Iberian hares (L. granatensis; Legr) were supplied by CIBIO, Vairão, Portugal. In addition, two brush rabbit (Sylvilagus bachmani; Syba) spleen samples were provided by the Blue Oak Ranch Reserve, University of California, USA. During this study, no experimental research on animals was conducted.

Total RNA was prepared using the guanidinium thiocyanate-phenol-chloroform extraction method (TRIzol) according to manufacturer's instructions (Molecular Research Center, Inc., Cincinnati, OH, USA). Firststrand cDNA was prepared from $5 \mu \mathrm{g}$ of total RNA, using oligo(dT) primers [59] and the SuperScript ${ }^{\mathrm{TM}}$ III First-Strand Synthesis System (Invitrogen, Carlsbad, CA, USA).

\section{TRIM5 $\alpha$ amplification, cloning and sequencing}

The sequence of the European rabbit subspecies $O$. $c$. cuniculus (Orcucu) TRIM5 $\alpha$ used in this study was taken from GenBank (accession number NM_001105673) [38]. A previously reported [40] American pika (Ochotona princeps; Ocpr) TRIM5 $\alpha$ nucleotide sequence retrieved from the whole genome shotgun (WGS) project (contig132533, Locus AAYZ01132534) was also included.

PCR primers were designed from the available sequence for European rabbit TRIM $5 \alpha$ cDNA (Forward 5'-TGTCTTGCAGAAATCTGTGAGCAAAAG-3' and Reverse 5'-AAGAGATGTACCCCAGGGTAAGAG-3'), generating an approximately $1.5 \mathrm{~kb}$ PCR product corresponding to the full-length CDS. The PCR thermal profile used was the following: initial denaturation $\left(98^{\circ} \mathrm{C}\right.$ for $30 \mathrm{~s})$; 40 cycles of denaturation $\left(98^{\circ} \mathrm{C}\right.$ for $\left.10 \mathrm{~s}\right)$, annealing $\left(60^{\circ} \mathrm{C}\right.$ for $\left.30 \mathrm{~s}\right)$ and extension $\left(72^{\circ} \mathrm{C}\right.$ for $\left.1 \mathrm{~min}\right)$; and a final extension $\left(72^{\circ} \mathrm{C}\right.$ for $\left.10 \mathrm{~min}\right)$. Phusion ${ }^{\circledR}$ High-Fidelity DNA Polymerase (Finnzymes, Espoo, Finland) was used. Finally, an additional extension step $\left(72^{\circ} \mathrm{C}\right.$ for 10 min) with Taq polymerase (GoTaq, Promega; Madison, WI, USA) was performed.

The PCR products were cloned into the pGEM-T Easy vector (Promega, Madison, WI, USA). At least seven independent clones were sequenced per allele. Sequencing was performed with an ABI PRISM 3130 Genetic Analyser (PE Applied Biosystems), following the ABI 
PRISM BigDye Terminator Cycle sequencing protocol. PCR products were sequenced in both directions and also with an internal primer (5' CCAACAGGAGATAACTTCCTGGAA 3'). Nucleotide sequence data obtained in this study have been submitted to GenBank and have been assigned the following accession numbers: JN541226, JN541227, JN541228, JN541229 and JN541230.

\section{Phylogenetic analyses}

In order to infer the Lagomorpha TRIM5 $\alpha$ phylogeny, based on nucleotide and deduced amino acid sequences, a Maximum Likelihood method implemented on GARLI 1.0 (Genetic Algorithm for Rapid Likelihood Inference) [60] was used. The analyses were performed with $1,000,000$ generations and 1,000 bootstrap searches. The Model TIM3 + G for nucleotide substitution estimation was used as indicated by the jModelTest 0.1.1 [61]. The JTT [62] mutation model applied to the amino acid deduced sequences was used with a rate variation among sites with 4 rate categories $(+G)$, as indicated by the program Prottest 2.4 [63-65].

\section{Codon-based analysis of positive selection}

Most proteins appear to be under strong purifying selection most of the time, whereas positive selection is relegated to small regions of the molecule, meaning that structural and functional domains are likely to evolve at different rates [66]. A common approach to detect selective pressures involves estimating the rates of nonsynonymous $\left(\mathrm{d}_{\mathrm{N}}\right)$ and synonymous $\left(\mathrm{d}_{\mathrm{S}}\right)$ substitutions [67]. The random effect likelihood (REL) model proposed by Kosakovsky and colleagues [67] and implemented in the Datamonkey web server [68] was used to identify TRIM5 $\alpha$ codons under positive selection. REL involves fitting a distribution of substitution rates across sites and then inferring the rate for individual sites [67]. The REL method under the MG94xHKY85 model of evolution was used. Normalized posterior mean of the $\mathrm{d}_{\mathrm{N}}-\mathrm{d}_{\mathrm{S}}$ difference and the Bayesian posterior probability for positive selection $\left(d_{N}>d_{S}\right)$ for each codon position were obtained. A Bayes factor of greater than 50 suggests that a site is positively selected.

Estimation of leporid TRIM5 $\alpha$ synonymous and nonsynonymous substitution rates, using the Nei-Gojobori method [50], was performed on MEGA5 [69].

\section{Sliding-window analysis}

An alternative approach to determine nucleotide substitution rate variation among different genomic regions is to plot differences as averages by sliding a window along a sequence alignment [70]. A sliding-window analysis was performed using DnaSP version 5.10 [71]. A window length of 90 nucleotides and a step size of 10 were chosen for this analysis. Nucleotide replacements per site between European rabbit/European brown hare, European rabbit/Iberian hare, European rabbit/brush rabbit, European rabbit/American pika, human/chimpanzee and human/rhesus monkey TRIM $5 \alpha$ were analyzed.

\section{Acknowledgements}

The Portuguese Foundation for Science and Technology supported the doctoral fellowship of Ana Lemos de Matos (SFRH/BD/48566/2008) and the post-doctoral fellowship of Pedro J. Esteves (SPRH/BPD/27021/2006). This work was also supported by a project of the Portuguese Foundation for Science and Technology (PTDC/BIA-BEC/103158/2008). We would like to thank Jeff Wilcox and Dr. Michael Hamilton from Blue Oak Ranch Reserve, University of California, Berkeley for providing brush rabbit (Sylvilagus bachmani) tissue samples.

\section{Author details}

${ }^{1}$ Centro de Investigação em Biodiversidade e Recursos Genéticos, Campus Agrário de Vairão, 4485-661 Vairão, Portugal. ²Departamento de Zoologia e Antropologia, Faculdade de Ciências, Universidade do Porto, 4169-007 Porto, Portugal. ${ }^{3}$ Department of Microbiology and Immunology, Stritch School of Medicine, Loyola University Chicago, Maywood, IL 60153, USA. ${ }^{4}$ Centro de Investigação em Tecnologias da Saúde, IPSN, CESPU, 4585-116 Gandra, Portugal.

\section{Authors' contributions}

ALM participated in the design of the experiments, performed the experiments, participated in the data analyses and drafted the manuscript. HA contributed in the evolutionary analysis. DKL and WvdL participated in drafts of the manuscript. PJE conceived the study, designed the experiments and drafted the manuscript. All authors read and approved the final manuscript.

Received: 4 May 2011 Accepted: 8 October 2011 Published: 8 October 2011

\section{References}

1. Boeke JD, Stoye JP: Retrotransposons, endogenous retroviruses, and the evolution of retroelements. In Retroviruses. Edited by: Coffin JM, Hughes SH, Varmus HE. CSHL Press, New York; 1997:343-435.

2. Petropoulos C: Retroviral taxonomy, protein structures, sequences, and genetic maps. In Retroviruses. Edited by: Coffin JM, Hughes SH, Varmus HE. CSHL Press, New York; 1997:757-805.

3. Gifford $R$, Tristem M: The evolution, distribution and diversity of endogenous retroviruses. Virus Genes 2003, 26:291-315.

4. Katzourakis A, Tristem M, Pybus OG, Gifford RJ: Discovery and analysis of the first endogenous lentivirus. Proc Natl Acad Sci USA 2007, 104:6261-6265.

5. Keckesova Z, Ylinen LMJ, Towers GJ, Gifford RJ, Katzourakis A: Identification of a RELIK orthologue in the European hare (Lepus europaeus) reveals a minimum age of 12 million years for the lagomorph lentiviruses. Virology 2009, 384:7-11.

6. van der Loo W, Abrantes J, Esteves PJ: Sharing of endogenous lentiviral gene fragments among leporid lineages separated for more than 12 million years. J Virol 2009, 83:2386-2388.

7. Stremlau M, Owens CM, Perron MJ, Kiessling M, Autissier P, Sodroski J: The cytoplasmic body component TRIM5a restricts HIV-1 infection in Old World monkeys. Nature 2004, 427:848-853.

8. Sayah DM, Sokolskaja E, Berthoux L, Luban J: Cyclophilin A retrotransposition into TRIM5 explains owl monkey resistance to HIV-1. Nature 2004, 430:569-573.

9. Nisole S, Stoye JP, Saïb A: TRIM family proteins: retroviral restriction and antiviral defence. Nat Rev Microbiol 2005, 3:799-808.

10. Ozato K, Shin D-M, Chang T-H, Morse HC: TRIM family proteins and their emerging roles in innate immunity. Nat Rev Immunol 2008, 8:849-860.

11. Reymond A, Meroni G, Fantozzi A, Merla G, Cairo S, Luzi L, Riganelli D, Zanaria E, Messali S, Cainarca S, Guffanti A, Minucci S, Pelicci PG, Ballabio A: 
The tripartite motif family identifies cell compartments. EMBO J 2001, 20:2140-2151.

12. Yamauchi K, Wada K, Tanji K, Tanaka M, Kamitani T: Ubiquitination of E3 ubiquitin ligase TRIM5a and its potential role. FEBS J 2008, 275:1540-1555

13. Javanbakht H, Diaz-Griffero F, Stremlau M, Si Z, Sodroski J: The contribution of RING and B-box 2 domains to retroviral restriction mediated by monkey TRIM5alpha. J Biol Chem 2005, 280:26933-26940.

14. Li X, Song B, Xiang SH, Sodroski J: Functional interplay between the BBOX 2 and the B30.2 (SPRY) domains of TRIM5a. Virology 2007, $366: 234-244$

15. Li X, Sodroski J: The TRIM5alpha B-box 2 domain promotes cooperative binding to the retroviral capsid by mediating higher-order selfassociation. J Virol 2008, 82:11495-11502.

16. Javanbakht H, Yuan W, Yeung DF, Song B, Diaz-Griffero F, Li Y, Li X, Stremlau M, Sodroski J: Characterization of TRIM5a trimerization and its contribution to human immunodeficiency virus capsid binding. Virology 2006, 353:234-246.

17. Yap MW, Nisole S, Stoye JP: A single amino acid change in the SPRY domain of human Trim5a leads to HIV-1 restriction. Curr Biol 2005, 15:73-78.

18. Stremlau M, Perron M, Welikala S, Sodroski J: Species-specific variation in the B30.2 (SPRY) domain of TRIM5a determines the potency of Human Immunodeficiency Virus restriction. J Virol 2005, 79:3139-3145.

19. Hatziioannou T, Perez-Caballero D, Yang A, Cowan S, Bieniasz PD: Retrovirus resistance factors Ref1 and Lv1 are species-specific variants of TRIM5alpha. Proc Natl Acad Sci USA 2004, 101:10774-10779.

20. Keckesova Z, Ylinen LM, Towers GJ: The human and African green monkey TRIM5alpha genes encode Ref1 and Lv1 retroviral restriction factor activities. Proc Natl Acad Sci USA 2004, 101:10780-10785.

21. Yap MW, Nisole S, Lynch C, Stoye JP: Trim5alpha protein restricts both HIV-1 and murine leukemia virus. Proc Natl Acad Sci USA 2004, 101:10786-10791.

22. Perron MJ, Stremlau M, Song B, UIm W, Mulligan RC, Sodroski J: TRIM5alpha mediates the postentry block to $\mathrm{N}$-tropic murine leukemia viruses in human cells. Proc Natl Acad Sci USA 2004, 101:11827-11832.

23. Li Y, Li X, Stremlau M, Lee M, Sodrosky J: Removal of arginine 332 allows human TRIM5alpha to bind human immunodeficiency virus capsids and to restrict infection. J Virol 2006, 80:6738-6744.

24. Sebastian S, Luban J: TRIM5alpha selectively binds a restriction-sensitive retroviral capsid. Retrovirology 2005, 2:40.

25. Song B, Gold B, O'hUigin C, Javanbakht H, Li X, Stremlau M, Winkler C, Dean M, Sodroski J: The B30.2 (SPRY) domain of the retroviral restriction factor TRIM5alpha exhibits lineage-specific length and sequence variation in primates. J Virol 2005, 79:6111-6121.

26. James LC, Keeble AH, Khan Z, Rhodes DA, Trowsdale J: Structural basis for PRYSPRY-mediated tripartite motif (TRIM) protein function. Proc Natl Acad Sci USA 2007, 104:6200-6205.

27. Tareen SU, Emerman M: Human TRIM5a has additional activities that are uncoupled from retroviral capsid recognition. Virology 2011, 409:113-120.

28. Pertel T, Hausmann S, Morger D, Züger S, Guerra J, Lascano J, Reinhard C, Santoni FA, Uchil PD, Chatel L, Bisiaux A, Albert ML, Strambio-De-Castillia C, Mothes W, Pizzato M, Grütter MG, Luban J: TRIM5 is an innate immune sensor for the retrovirus capsid lattice. Nature 2011, 472:361-365.

29. Ganser-Pornillos BK, Chandrasekaran V, Pornillos O, Sodroski JG, Sundquist WI, Yeager M: Hexagonal assembly of a restricting TRIM5alpha protein. Proc Natl Acad Sci USA 2011, 108:534-539.

30. Zhao G, Ke D, Vu T, Ahn J, Shah VB, Yang R, Aiken C, Charlton LM, Gronenborn AM, Zhang P: Rhesus TRIM5a disrupts the HIV-1 capsid at the inter-hexamer interfaces. PLoS Pathog 2011, 7:e1002009.

31. Sawyer SL, Wu LI, Emerman M, Malik HS: Positive selection of primate TRIM5a identifies a critical species-specific retroviral restriction domain. Proc Natl Acad Sci USA 2005, 102:2832-2837.

32. Johnson WE, Sawyer SL: Molecular evolution of the antiretroviral TRIM5 gene. Immunogenetics 2009, 61:163-176.

33. Soares EA, Menezes AN, Schrago CG, Moreira MAM, Bonvicino CR, Soares MA, Seuánez HN: Evolution of TRIM5a B30.2 (SPRY) domain in New World primates. Infect Genet Evol 2010, 10:246-253.

34. Newman RM, Hall L, Connole M, Chen G-L, Sato S, Yuste E, Diehl W, Hunter E, Kaur A, Miller GM, Johnson WE: Balancing selection and the evolution of functional polymorphism in Old World monkey TRIM5a. Proc Natl Acad Sci USA 2006, 103:19134-19139.
35. Cagliani R, Fumagalli M, Biasin M, Piacentini L, Riva S, Pozzoli U, Bonaglia MC, Bresolin N, Clerici M, Sironi M: Long-term balancing selection maintains trans-specific polymorphisms in the human TRIM5 gene. Human Genet 2010, 128:577-588.

36. Si Z, Vandegraaff N, O'hUigin C, Song B, Yuan W, Xu C, Perron M, Li X, Marasco WA, Engelman A, Dean M, Sodroski J: Evolution of a cytoplasmic tripartite motif (TRIM) protein in cows that restricts retroviral infection. Proc Natl Acad Sci USA 2006, 103:7454-7459.

37. Sawyer SL, Emerman M, Malik HS: Discordant evolution of the adjacent antiretroviral genes TRIM22 and TRIM5 in mammals. PLoS Pathog 2007, 3: e197.

38. Schaller T, Hué S, Towers GJ: An active TRIM5 protein in rabbits indicates a common antiviral ancestor for mammalian TRIM5 proteins. J Virol 2007, 81:11713-11721.

39. Tareen SU, Sawyer SL, Malik HS, Emerman M: An expanded clade of rodent Trim5 genes. Virology 2009, 385:473-483.

40. Fletcher AJ, Hué S, Schaller T, Pillay D, Towers GJ: Hare TRIM5a restricts divergent retroviruses and exhibits significant sequence variation from closely related Lagomorpha TRIM5 genes. J Virol 2010, 84:12463-12468.

41. Matthee $C A$, van Vuuren BJ, Bell D, Robinson TJ: A molecular supermatrix of the rabbits and hares (Leporidae) allows for the identification of five intercontinental exchanges during the Miocene. Syst Biol 2004, 53:433-447.

42. Matthee CA: Pikas, hares and rabbits (Lagomorpha). In The timetree of life. Edited by: Hedges SB, Kumar S. Oxford University Press, New York, NY; 2009:487-489.

43. Lanier HC, Olson LE: Inferring divergence times within pikas (Ochotona spp.) using mtDNA and relaxed molecular dating techniques. $\mathrm{Mol}$ Phylogenet Evol 2009, 53:1-12.

44. Ferrand N, Branco M: The evolutionary history of the European rabbit (Oryctolagus cuniculus): major patterns of population differentiation and geographic expansion inferred from protein polymorphism. In Phylogeography of Southern European Refugia. Edited by: Weiss S, Ferrand N. Springer, The Netherlands; 2007:207-235

45. Carmo CR, Esteves PJ, Ferrand N, van der Loo W: Genetic variation at chemokine receptor CCR5 in leporids: alteration at the 2 nd extracellular domain by gene conversion with CCR2 in Oryctolagus, but not in Sylvilagus and Lepus species. Immunogenetics 2006, 58:494-501.

46. Abrantes J, Carmo CR, Matthee CA, Yamada F, van der Loo W, Esteves PJ: A shared unusual genetic change at the chemokine receptor type 5 between Oryctolagus, Bunolagus and Pentalagus. Conserv Genet 2011, 12:325-330.

47. Esteves PJ, Lanning D, Ferrand N, Knight KL, Zhai SK, van der Loo W: The evolution of the immunoglobulin heavy chain variable region $\left(\lg V_{H}\right)$ in Leporids: an unusual case of transspecies polymorphism. Immunogenetics 2005, 57:874-882.

48. Siepel A: Phylogenomics of primates and their ancestral populations. Genome Res 2009, 19:1929-1941.

49. Takahata N, Satta Y: Evolution of the primate lineage leading to modern humans: phylogenetic and demographic inferences from DNA sequences. Proc Natl Acad Sci USA 1997, 94:4811-4815.

50. Nei M, Gojobori T: Simple methods for estimating the numbers of synonymous and nonsynonymous nucleotide substitutions. Mol Biol Evol 1986, 3:418-426.

51. Johnson WE, Coffin JM: Constructing primate phylogenies from ancient retrovirus sequences. Proc Natl Acad Sci USA 1999, 96:10254-10260.

52. Emerman M, Malik HS: Paleovirology - Modern consequences of ancient viruses. PLOS Biol 2010, 8:e1000301.

53. Kerns JA, Emerman M, Malik HS: Positive selection and increased antiviral activity associated with the PARP-containing isoform of human zincfinger antiviral protein. PLoS Genet 2008, 4:e21.

54. Elde NC, Child SJ, Geballe AP, Malik HS: Protein kinase R reveals an evolutionary model for defeating viral mimicry. Nature 2009, 457:485-489.

55. Kaiser SM, Malik HS, Emerman M: Restriction of an extinct retrovirus by the human TRIM5a antiviral protein. Science 2007, 316:1756-1758.

56. Goldstone DC, Yap MW, Robertson LE, Haire LF, Taylor WR, Katzourakis A, Stoye JP, Taylor IA: Structural and functional analysis of prehistoric lentiviruses uncovers an ancient molecular interface. Cell Host Microbe 2010, 8:248-259. 
57. Gamble TR, Vajdos FF, Yoo S, Worthylake DK, Houseweart M, Sundquist WI, Hill CP: Crystal structure of human cyclophilin A bound to the aminoterminal domain of HIV-1 capsid. Cell 1996, 87:1285-1294.

58. Luban J, Bossolt KL, Franke EK, Kalpana GV, Goff SP: Human immunodeficiency virus type $1 \mathrm{Gag}$ protein binds to cyclophilins A and B. Cell 1993, 73:1067-1078.

59. Krug MS, Berger SL: First-strand CDNA synthesis primed with oligo(dT) Methods Enzymol 1987, 152:316-325.

60. Zwickl DJ: Genetic algorithm approaches for the phylogenetic analysis of large biological sequence datasets under the maximum likelihood criterion. PhD thesis University of Texas, Austin; 2006

61. Posada D: jModelTest: Phylogenetic Model Averaging. Mol Biol Evol 2008, 25:1253-1256.

62. Jones DT, Taylor WR, Thornton JM: The rapid generation of mutation data matrices from protein sequences. CABIOS 1992, 8:275-282.

63. Abascal F, Zardoya R, Posada D: ProtTest: Selection of best-fit models of protein evolution. Bioinformatics 2005, 21:2104-2105.

64. Drummond A, Strimmer K: PAL: An object-oriented programming library for molecular evolution and phylogenetics. Bioinformatics 2001, 17:662-663.

65. Guindon S, Gascuel O: A simple, fast, and accurate algorithm to estimate large phylogenies by maximum likelihood. Syst Biol 2003, 52:696-704.

66. Fares MA, Elena SF, Ortiz J, Moya A, Barrio E: A sliding window-based method to detect selective constraints in protein-coding genes and its application to RNA viruses. J Mol Evol 2002, 55:509-521.

67. Kosakovsky Pond SL, Frost SD: Not so different after all: a comparison of methods for detecting amino acid sites under selection. Mol Biol Evol 2005, 22:1208-1222.

68. Kosakovsky Pond SL, Frost SD: Datamonkey: rapid detection of selective pressure on individual sites of codon alignments. Bioinformatics 2005, 21:2531-2533.

69. Tamura K, Peterson D, Peterson N, Stecher G, Nei M, Kumar S: MEGA5: Molecular Evolutionary Genetics Analysis using Maximum Likelihood, Evolutionary Distance, and Maximum Parsimony Methods. Mol Biol Evol 2011, 28:2731-2739.

70. Tajima F: Determination of window size for analysing DNA sequences. Mol Evol 1991, 33:470-473.

71. Librado P, Rozas J: DnaSP v5: A software for comprehensive analysis of DNA polymorphism data. Bioinformatics 2009, 25:1451-1452.

doi:10.1186/1471-2148-11-294

Cite this article as: de Matos et al: Study of Sylvilagus rabbit TRIM5 $\alpha$ species-specific domain: how ancient endoviruses could have shaped the antiviral repertoire in Lagomorpha. BMC Evolutionary Biology 2011 11:294.

\section{Submit your next manuscript to BioMed Central and take full advantage of:}

- Convenient online submission

- Thorough peer review

- No space constraints or color figure charges

- Immediate publication on acceptance

- Inclusion in PubMed, CAS, Scopus and Google Scholar

- Research which is freely available for redistribution 